\title{
Evaluation of $\mathrm{O}_{3}$ and NOx Pollution Based on People's Perception
}

\author{
Yuping Jiang*, Andong Zhu, Shuwei Jiang, Zhengguan Li, Cezuan Yang \\ School of Materials Science and Food Engineering, University of Electronic Science and Technology of China, \\ Zhongshan Institute, Zhongshan City 528400, Guangdong Province, China
}

Received: 31 January 2021

Accepted: 24 May 2021

\begin{abstract}
Both $\mathrm{NOx}$ and $\mathrm{O}_{3}$ are irritants and harmful pollutants for human health, and it is very reasonable and important to evaluate their effects by combining public perceptions. Five groups of pollutant concentrations and scores (98 healthy people) were available at the same site. Using the optimal Weber constant and Weber-Fischna-Law (W-F-L) change, the results showed that $\mathrm{O}_{3}$ and NOx were the main irritants compared with other factors in our experiment, and most assessments were approximately in agreement with the pollution level and people's perception rules. In addition, due to the lack of calculation unity and the essential concept for the present Weber constant, the true value based on real human perceptions was first obtained based on the findings that the exact match between concentrations and score means was the unique breakthrough.
\end{abstract}

Keywords: air pollution, concentration, score, Weber Fischna Law

\section{Introduction}

$\mathrm{NOx}$ and $\mathrm{O}_{3}$ investigations in terms of their physical and chemical properties are currently of great concern. $\mathrm{NO}_{2}$ is a key precursor for a range of secondary pollutants [1], such as $\mathrm{O}_{3}$, and can cause damage to humans, animals, vegetation, and materials [2], and increase susceptibility to respiratory infections [3]. A linear relationship between $\mathrm{O}_{3}$ and mortality has also been found [4], which could be explained by the fact that pollutants are easily absorbed by humans, thereby impairing lung function [5-6]. In addition, $\mathrm{O}_{3}$ has been increasingly associated with climate change [7]. These two pollutants also produce negative synergistic effects

*e-mail: zsxyjyp@126.com with particulate matter and $\mathrm{SO}_{2}$ in many diseases in which their relative risks (RRs) are statistically significant and the highest [8]. Although there are some natural emissions of NOx, the majority of emissions are from anthropogenic sources [9], in which coal and biomass are regarded as the major sources of emissions in northeastern China [10], and urban-traffic $\mathrm{NO}_{2}$ has increased the COVID-19 pandemic fatality rate [11]. $\mathrm{O}_{3}$ pollution is also serious due to its close relationship with NOx.

Therefore, it is very important to evaluate the effects of $\mathrm{O}_{3}$ and $\mathrm{NOx}$, especially on human health. In general, large data analyses have been widely used, such as utilizing a Poisson regression model to find the associations between $\mathrm{O}_{3}$ and $\mathrm{NO}_{2}$ and disease mortality in Panama City [12] and assessing the effects from $\mathrm{PM}$ and $\mathrm{NO}_{2}$ on health indicators [13]. The large and synergistic effects of $\mathrm{O}_{3}, \mathrm{NO}_{2}$, and 
other pollutants have also been studied in respiratory and related diseases [14]. In fact, human perception, which combines physiology and psychology, is a part of health or is an indicator. Perception can thus show the influence on health and public satisfaction of air quality, in which perceptions change with the stimulus, which includes pollution according to the Weber-Fischna Law (W-F-L). Unfortunately, relevant research is very scarce. Although a few assessments of gas quality have been reported [15-17], they are only nominal evaluations of people's perceptions. It is still unknown which and how perceptions of a person agree with the law. The only research in recent years has been to accurately perceive indoor formaldehyde pollution through smell, in which perceptions could match the pollutant concentration [18].

Since the harm from $\mathrm{O}_{3}$ and $\mathrm{NOx}$ to humans is attracting increasing attention, people's perception cannot be ignored, especially according to the basic law (W-F-L). Therefore, the aim of this study is to examine the relationship between $\mathrm{O}_{3}$ and $\mathrm{NO}_{x}$ pollution and human perceptions through the nose, eyes and throat based on the W-F-L. In addition, the true Weber constant based on people's perceptions is obtained.

\section{Materials and Methods}

\section{Study Design}

$\mathrm{O}_{3}$ and $\mathrm{NOx}$ were determined according to the China environmental standards (HJ 504-2009 and HJ 479-2017, respectively), hourly $\mathrm{O}_{3}$ and NOx concentration data were available from three simultaneous monitoring recordings at the same site, and the arithmetic mean was selected as the experimental value (shown in Table 1). In addition, for the influence of pollution on the throat, nose and vision, random sampling of a face-to-face questionnaire survey was conducted among 98 effective people who could pass the corresponding health questionnaire test near the monitoring site, in which participants scored their physiological sensations from a range of 1 to 5. The grade of fractions is presented in Table 2. In the experiment, the proportion of males to females was 20:29, and the age distributions, $20.1 \%$, $40.8 \%$ and $39.1 \%$, were in the ranges of $20-35,35-50$ and 50-65 years, respectively.

\section{Pollution Assessment}

Using the pollutant concentrations and questionnaire scores, conventional assessments were performed. In addition, the data were changed by the W-F-L of Eq. (1):

$$
\mathrm{K}=\alpha \lg (1+\mathrm{S})
$$

...where $\mathrm{K}$ is the Weber exponent, the intensity of a person's perception; $a$ is the Weber constant, which is only related to the species and property of pollutant and type of perception, but not to concentration; and $\mathrm{S}$ is the outer stimulating strength, the pollutant concentrations and questionnaire scores. In this study, the $(1+\mathrm{S})$ method was used to ensure $\lg (\mathrm{c}+1) \geq 0$ and did not influence the results of the evaluation.

Table 1. Grade and Measured Value.

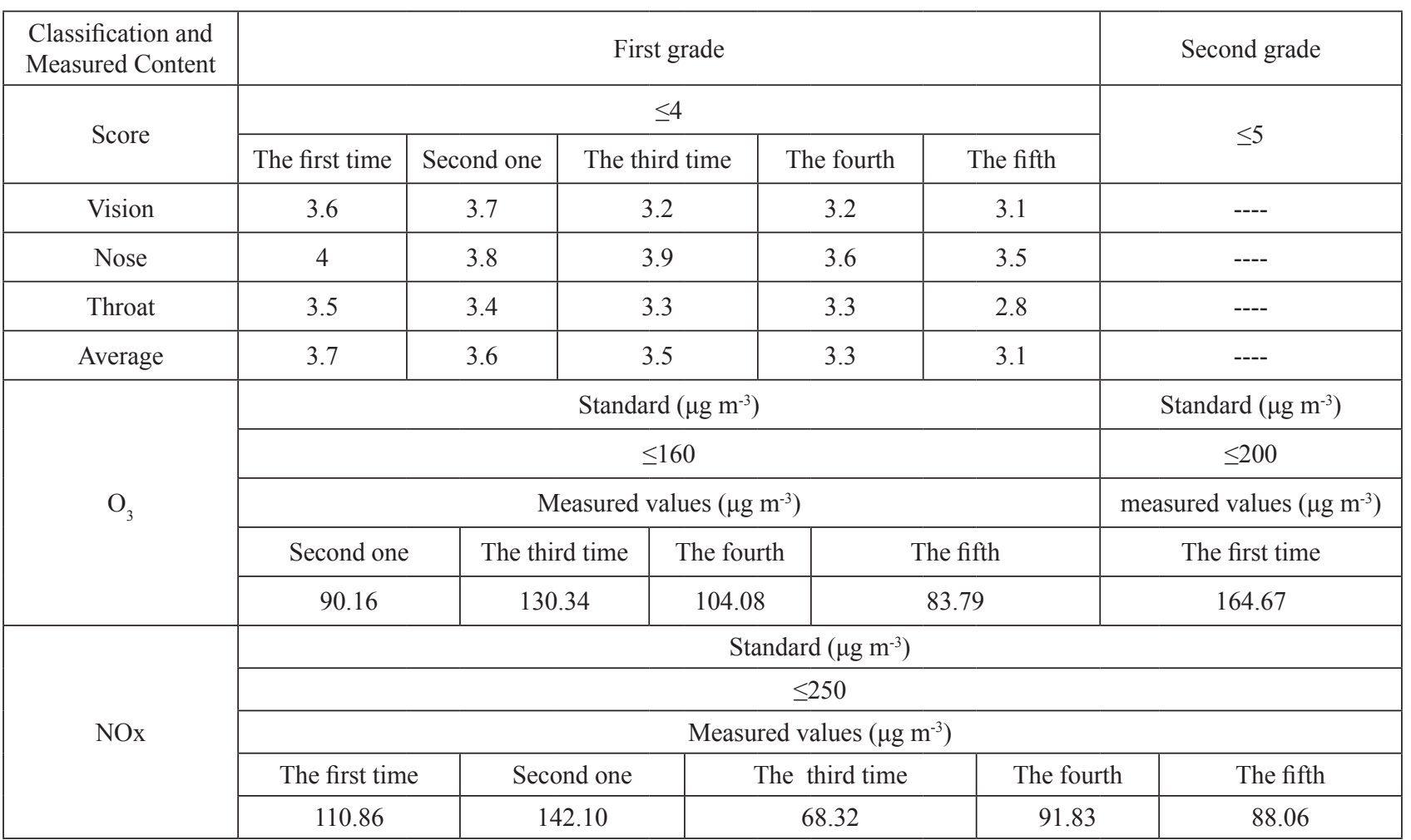


Table 2. Fraction grade.

\begin{tabular}{|c|c|c|c|c|c|}
\hline \multirow{2}{*}{$\begin{array}{c}\text { Physiological } \\
\text { perception }\end{array}$} & A & B & C & D & E \\
\cline { 2 - 6 } & Weak & Weaker & Strong & Stronger & Strongest \\
\hline Fraction & 1 & 2 & 3 & 4 & 5 \\
\hline
\end{tabular}

\section{Results and Discussion}

\section{The Optimal Weber Constants}

According to the China Environmental Standard (GB3095-2012), the 1-hour average limit of $\mathrm{O}_{3}$ and $\mathrm{NO}_{\mathrm{x}}$ is divided into two grades, and the scores are also graded according to the rate of $\mathrm{O}_{3}$. Combining the measured values, the results are shown in Table 2.

It is necessary for the W-F-L to clearly reflect the difference in degree of different grades and the concentrations in the same grade, in which a is very important. Therefore, using the study method [18], according to Eqs (2) and (3), the a for pollutants, throat, nose, eyes and scores were obtained, as shown in Table 3.

$$
\begin{gathered}
\min (\geq 0)=\sum_{i=1}^{4}\left[\lg (160)-\operatorname{aclg}\left(c_{i, O_{3}}\right)\right]+\sum_{i=1}^{5}[\lg (250) \\
\left.-\operatorname{aclg}\left(c_{i, N O x}\right)\right]+\left[\lg (200)-\operatorname{aclg}\left(c_{5, O_{3}}\right)\right]-\left[\operatorname{aclg}\left(c_{5, O_{3}}\right)\right. \\
\left.-\operatorname{aclg}\left(c_{4, O_{3}}\right)\right]
\end{gathered}
$$

$$
\begin{aligned}
\min (\geq 0)=\sum_{i=1}^{m} & {\left[\lg (4)-a_{k} \lg \left(f_{k i}\right)\right]+\sum_{i=m}^{98}\left[\lg (5)-a_{k} \lg \left(f_{k i}\right)\right] } \\
- & {\left[a_{k} \lg \left(f_{k, m+1}\right)-a_{k} \lg \left(f_{k m}\right)\right] }
\end{aligned}
$$

...where 160 and 200, 250, and 4 and 5 are the grade standards of $\mathrm{O}_{3}, \mathrm{NOx}$ and the score, respectively; $\mathrm{a}_{c}$ is the Weber constants for pollutant concentrations; $a_{k}$ is for the different and average pollution irritations in which $\mathrm{k}$ is $1,2,3$, or 4 representing throat, nose, or vision irritation, respectively, and the mean of three perceptions; $f_{k i}, f_{k m}$ and $f_{k, m+1}$ are the ith, $m$ th and $(m+1)$ th scores, respectively, for the $\mathrm{k}$ pollution irritation, in which $f_{k m}$ and $f_{k, m+1}$ are the demarcation values for the score grade.

Table 3. Weber Constant for Different Objects.

\begin{tabular}{|c|c|}
\hline Object & $\mathrm{a}$ \\
\hline Pollutant concentration & 1.13 \\
\hline Vision influence & 1.38 \\
\hline Throat irritation & 1.48 \\
\hline Nose irritation & 1.35 \\
\hline Perception mean & 1.37 \\
\hline
\end{tabular}

Since the specific pollutants were the same, the change in the Weber constant was related to the type of perception and other influencing factors (such as aerosols and psychology). It is interesting that for the real concentration and people's perceptions, the Weber constant distribution is relatively uniform, and every value distance is small, in which their relative mean error is $5.6 \%$. The results show that in the experiment, $\mathrm{O}_{3}$ and NOx are the main irritation sources compared with the other factors, which also improved the experimental design. In addition, the calculated values are very close to 1 , which is the selected level of the constant for different grade standards; thus, selection is important. In our experiment, no influence of $\mathrm{K}$ was determined in principle, but there were various ways and a lack of unity.

\section{The Assessment by Pollutant Concentration}

Basing on the data and Eq. (1), $\mathrm{K}$ could be acquired and is shown in Table 4, including the values according to the arithmetic mean of the two pollutant concentrations.

For the standard and measurement changes, their Weber exponents are in agreement with each other. In addition, due to the property of logarithms, the calculated data are closer to each other than the real concentrations, because the ability for humans to perceive pollution differences is obviously lower than the measurements. All results mentioned above are in accordance with changes in human perception; thus, similar methods are usually used to assess environmental quality through fitting, integration and so on $[16,18]$.

\section{The Evaluation by Scores}

All score assessments in Table 2 were synthetic evaluations corresponding to most pollutant concentrations in the first grade, which show that the evaluation based on human perception can approximately reflect the pollution. Indeed, a similar method, especially direct scoring, is usually used in public participation on environmental problems and is very helpful in assessing and solving the issue. Through logarithmic change, Table 5 also displays the tightness for each value, which are similar to the concentration results mentioned above, which caused the change rate to always be lower than the real scores and concentrations, abiding by the law of people's perceptions. On the other hand, due to physiological 
Table 4. Weber Exponent of Pollutant Concentration.

\begin{tabular}{|c|c|c|c|c|c|c|c|}
\hline \multirow{2}{*}{ Pollution } & \multicolumn{7}{|c|}{ K } \\
\hline & \multicolumn{2}{|c|}{ Standard change } & \multicolumn{5}{|c|}{ Measurement change } \\
\hline \multirow{4}{*}{$\mathrm{O}_{3}$} & \multirow{2}{*}{ First grade } & \multirow{2}{*}{$\leq 2.49$} & Second one & \multicolumn{2}{|c|}{ The third time } & The fourth & The fifth \\
\hline & & & 2.21 & \multicolumn{2}{|c|}{2.39} & 2.30 & 2.17 \\
\hline & \multirow{2}{*}{ Second grade } & \multirow{2}{*}{$\leq 2.60$} & \multicolumn{5}{|c|}{ The first time } \\
\hline & & & \multicolumn{5}{|c|}{2.50} \\
\hline \multirow{2}{*}{ NOx } & \multirow{2}{*}{ Grade } & \multirow{2}{*}{$\leq 2.71$} & The first time & $\begin{array}{l}\text { Second } \\
\text { one }\end{array}$ & The third time & The fourth & The fifth \\
\hline & & & 2.31 & 2.43 & 2.07 & 2.22 & 2.20 \\
\hline \multirow[t]{2}{*}{ Arithmetic mean } & First grade & $\leq 2.62$ & 2.42 & 2.33 & 2.26 & 2.25 & 2.19 \\
\hline & Second grade & $\leq 2.66$ & \multicolumn{5}{|c|}{--------- } \\
\hline
\end{tabular}

Table 5. Weber Exponent of Scores.

\begin{tabular}{|c|c|c|c|c|c|c|c|}
\hline \multirow{3}{*}{ Perception } & \multicolumn{7}{|c|}{$\mathrm{K}$} \\
\hline & \multirow{2}{*}{\multicolumn{2}{|c|}{ Grade change }} & \multicolumn{5}{|c|}{ Investigation change } \\
\hline & & & The first time & Second one & The third time & The fourth & The fifth \\
\hline \multirow{2}{*}{ Vision } & First Grade & $\leq 0.99$ & 0.77 & 0.78 & 0.70 & 0.70 & 0.68 \\
\hline & Second Grade & $\leq 1.07$ & & & & & \\
\hline \multirow{2}{*}{ Nose } & First Grade & $\leq 0.94$ & 0.81 & 0.78 & 0.80 & 0.75 & 0.73 \\
\hline & Second Grade & $\leq 1.05$ & & & & & \\
\hline \multirow{2}{*}{ Throat } & First Grade & $\leq 1.03$ & 0.81 & 0.79 & 0.77 & 0.75 & 0.66 \\
\hline & Second Grade & $\leq 1.15$ & & & & & \\
\hline \multirow{2}{*}{ Arithmetic mean } & First Grade & $\leq 1.03$ & 0.64 & 0.63 & 0.61 & 0.59 & 0.56 \\
\hline & Second Grade & $\leq 1.15$ & & & & & \\
\hline
\end{tabular}

and psychological limitations in humans, the sores are not completely in accordance with the real measurement data; for example, in Tables 2 and 5, a single $\mathrm{O}_{3}$ pollution value $\left(164.67 \mu \mathrm{g} / \mathrm{m}^{3}\right)$ in the second grade was not expressed; moreover, most values did not have effective relevance to the measurement data.

\section{The Weber Constant for Real People's Perceptions}

In the physiology and psychology experiment, the Weber constant a is obtained using Eq. (4), which unfolds its essential concept and calculation:

$$
\alpha=\frac{\Delta \mathrm{I}}{\mathrm{I}}
$$

...where $\Delta \mathrm{I}$ is the difference threshold for perception related to I (the initial stimulation strength), which is the real concentration in our experiment.
Therefore, the Weber constants enumerated in Table 3 for different objects are only nominal data, which can support the assessment by using complete concentrations but not real human perceptions. The true expression by using people's perceptions must depend on Eq. (4), in which the key was to find the accurate matching between the initial perception data and measured concentrations. Thus, the two kinds of values must have strong and significant correlations based on Pearson and Spearman correlation coefficients (coefficient $>0.9$, significance $<0.05$ ) because the Pearson test can show a close relationship between absolute counts of human perceptions and outer stimulations, the Spearman test display that of data interval. Using SPSS, significant correlations using Pearson tests were first performed, as shown in Table 6, in which only means of the scores and concentrations can satisfy the demand. Then, the two groups of averages also passed the Spearman test, as shown in Table 7. Thus, the minimal distance of the concentration mean (99.33-97.96) and corresponding value (99.33) could be used as $\Delta \mathrm{I}$ and I, 
Table 6. Significant Correlation of the Pearson Test.

\begin{tabular}{|c|c|c|c|c|c|}
\hline & & Vision Score & Nose Score & Throat Score & Score Mean \\
\hline $\mathrm{O}_{3}$ Concentration & Significance & 0.620 & 0.080 & 0.216 & 0.250 \\
\hline NOx Concentration & Significance & 0.051 & 0.766 & 0.459 & 0.312 \\
\hline Concentration Mean & Significance & 0.063 & 0.092 & 0.063 & $\mathbf{0 . 0 2 6}($ Coefficient $=\mathbf{0 . 9 2 1})$ \\
\hline
\end{tabular}

Table 7. Correlation of the Spearman Test.

\begin{tabular}{|l|c|c|}
\hline & & Score Mean \\
\hline \multirow{2}{*}{ Concentration Mean } & Significance & - \\
\cline { 2 - 3 } & Coefficient & 1 \\
\hline
\end{tabular}

respectively, and the real $a=0.014$, which is the real Weber constant of people's perceptions combined with nose, vision and throat for $\mathrm{NOx}$ and $\mathrm{O}_{3}$ pollution.

\section{Conclusion}

For air pollution, it is very important to use various methods to assess the influence on the public. Although both the initial concentration and the score data could be used to evaluate $\mathrm{O}_{3}$ and NOx pollution, the assessment through value changes was in agreement with human perception law, using the W-F-L with the optimal Weber constant, in which the Weber constants were relatively uniform and depended on the determining principle. In addition, if the evaluation was closer to true human perceptions, it was more beneficial to health; thus, the study found that the concentration and score means could exactly match each other, which proved that people's perceptions had a comprehensive effect corresponding to $\mathrm{O}_{3}$ and NOx. Thus, the W-F-L can be used not only in the evaluation of pollutant values but also in the assessment of people's true perceptions regarding pollution.

\section{Acknowledgments}

This research was financially supported by the characteristic innovation project of Guangdong Universities (Grant No. 2020KTSCX183) and the science project of Zhanshan City (Grant No. 2019B2015).

\section{Conflict of Interest}

The authors declare no conflict of interest.

\section{References}

1. SOLANGE C., JOANA F., CARLOS S., CARLA C., DIOGO L., HÉlDER R., CARLOS B., PETER R.,
ANA I. M., JOÃO P. T. Integrating Health on Air Quality Assessment-Review Report on Health Risks of Two Major European Outdoor Air Pollutants: PM and $\mathrm{NO}_{2}$, Journal of Toxicology and Environmental Health. Part B, 17, 327, 2014.

2. COLLIVIGNARELli M.C., DE R.C., ABBA A., BALDI M., BERTANZA G., PEDRAZZANI R., SORLINI S., CARNEVALE M.M. Analysis of lockdown for CoViD-19 impact on $\mathrm{NO}_{2}$ in London, Milan and Paris: What lesson can be learnt? Process safety and environmental protection: transactions of the Institution of Chemical Engineers, Part B. 146, 955, 2021.

3. ZEINAB G., MEHDI V., YASER T.B., ABDOLKAZEM N., GHOLAMREZA G., AFSHIN T. Prediction of $\mathrm{O}_{3}$ in the respiratory system of children using the artificial neural network model and with selection of input based on gamma test, ahvaz, iran. Environmental science and pollution research international. 26, 10945, 2019.

4. NEISI A., VOSOUGHI M., SHIRMARDI M., IDANI E., GOUDARZI G., HAZRATI S., MOHAMMADI M.J., ASADI A., ASGHARNIA H., HASHEMZADEH B., RAHMAT Z.G. Concentration of air pollutants as toxic matter in urban and rural areas of Ahvaz. Toxin Review. 37 (3), 244, 2018.

5. LIU S. K., CAI S., XIAO B., CHEN Y., XIANG X.D. The effect of pollutional haze on pulmonary function, J. Thorac Dis., 8 (1), E45, 2016.

6. JIAYAO Z., HONG S., QI, C., JIE G., ZHEN D., YAN X. Effects of individual ozone exposure on lung function in the elderly:a cross-sectional study in China, Environmental Science and Pollution Research, 26, 11692, 2019.

7. NGUYEN G.T.H., SHIMADERA H., URANISHI K., MATSUO T., KONDO A. Numerical assessment of PM ${ }_{25}$ and $\mathrm{O}_{3}$ air quality in Continental Southeast Asia: Impacts of potential future climate change. ATMOSPHERIC ENVIRONMENT, 215, 3, 2019.

8. WILSON W.S.T., TZE W.W., WONG A.H.S. Association between air pollution and daily mortality and hospital admission due to ischaemic heart diseases in Hong Kong, Atmospheric Environment, 120, 365, 2015.

9. DETLEF P. VAN-V., LEX F.B., STEVEN J.S., FRANK D. Global projections for anthropogenic reactive nitrogen emissions to the atmosphere: an assessment of scenarios in the scientific Literature, Curr. Opin. Env. Sust., 3, 362, 2011.

10. ZHAO Z.Y., CAO F., FAN M.Y., ZHANG W.Q., ZHANG Y.L., WANG Q., ZHANG Y.L. Coal and biomass burning as major emissions of nox in northeast china: implication from dual isotopes analysis of fine nitrate aerosols. Atmospheric Environment, 242, 190, 2020.

11. CHAKRABORTY P., JAYACHANDRAN S., PADALKAR P., SITLHOU L., SRIVASTAVA M. Exposure to nitrogen dioxide $\left(\mathrm{NO}_{2}\right)$ from vehicular emission could increase the covid-19 pandemic fatality in india: a perspective. Bulletin of Environmental Contamination and Toxicology, 105 (5), 200, 2020. 
12. ZÚÑIGA J., TARAJIA M., HERRERA, V.,URRIOLA W., GÓMEZ B., MOTTA J. Assessment of the Possible Association of Air Pollutants $\mathrm{PM}_{10}, \mathrm{O}_{3}, \mathrm{NO}_{2}$ With an Increase in Cardiovascular, Respiratory, and Diabetes Mortality in Panama City: A 2003 to 2013 Data Analysis, Medicine. 95 (2), e2464, 2016.

13. DEEPAK S., AMITKUMAR K.K., BUPENDER S., USHAMINA B. B.S., VINOD K.J. Statistical modeling of $\mathrm{O}_{3}$, NOx, CO, $\mathrm{PM}_{2.5}$, VOCs and noise levels in commercial complex and associated health risk assessment in an academic institution. Science of the Total Environment, 572, 589, 2016

14. WANG Y., ZU Y., HUANG L., ZHANG H., WANG C., HU J. Associations between daily outpatient visits for respiratory diseases and ambient fine particulate matter and ozone levels in Shanghai, China. Environmental Pollution, 240, 759, 2018.

15. CORI L., DONZELLI G., GORINI F., BIANCHI F., CURZIO O. Risk perception of air pollution: a systematic review focused on particulate matter exposure International Journal of Environmental Research and Public Health, 17 (6424), 11, 2020.

16. LI Z., WANG J., ZHANG G. A Universal Weber Exponential Formula on Air Quality Based on WeberFischna Law, Environmental Monitoring in China, 26 (2), 60, 2010.

17. BUONOCORE C., DE VECCHI R., SCALCO V., LAMBERTS R. Influence of relative air humidity and movement on human thermal perception in classrooms in a hot and humid climate. Building and Environment, 146, 100,2018

18. JIANG Y.P., LIU Y., CHEN M.J., LI M.F. Assessment of formaldehyde pollution based on Weber exponent and perception of people's smell, International Journal of Environmental Science and Technology, 14, 1470, 2017. 